\title{
Preparation, characterization, intrinsic dissolution studies and microbiological assessment of dapsone tosylate polymorphs
}

\author{
Daniela Flores-Pacheco', Karina Mondragón-Vásquez², Jorge G Domínguez- \\ Chávez ${ }^{2}$, Blanca E Duque-Montaño ${ }^{1}$, Oscar Torres-Ángeles ${ }^{1}$, Jesús Rivera- \\ Islas ${ }^{1 *}$ \\ ${ }^{1}$ Facultad de Farmacia, Universidad Autónoma del Estado de Morelos, Av. Universidad 1001, Cuernavaca 62209, ${ }^{2}$ Facultad de \\ Bioanálisis-Campus Veracruz, Universidad Veracruzana, Agustín de Iturbide s/n esq Carmen Serdán, Veracruz 91700, México
}

*For correspondence: Email: rij@uaem.mx; Tel: (+52) 7773297000 ext 3870

\begin{abstract}
Purpose: To prepare dapsone tosylate salt (TD) and its two polymorphs (TD-I and TD-II), and study their intrinsic dissolution profiles and preliminary anti-mycobacterium activity.

Methods: The synthesized product was studied with respect to the effect of solvent selection, reaction temperature and evaporation rate on the solid phase obtained. The polymorphs were characterized using powder $x$-ray diffraction (PXRD), proton nuclear magnetic resonance $\left({ }^{1} H\right.$-NMR), Fourier transform infrared spectroscopy (FT-IR), differential scanning calorimetry (DSC) and thermogravimetric analysis (TGA). UV/Vis spectroscopy was employed for quantification of the salt, while Wood apparatus was used for dissolution studies. Microdilution assay, using a 96-well equipment, was employed for the evaluation of anti-mycobacterial activity.

Results: On analysis of the solids obtained from synthesis with PXRD, two different patterns were observed. One pattern belonged to TD-I, previously reported, and the other was a new polymorph TD-II. Solvent evaporation was important in the selective preparation of TD-I or TD-II. Analyses with DSC, TGA and ${ }^{1} \mathrm{H}$-NMR revealed the absence of solvent in both solids and showed that TD-II was not a solvated salt. Spectral analysis with FT-IR demonstrated structural relationship between TD-I and TD-II. Intrinsic dissolution studies showed that both polymorphs dissolved faster than dapsone (DAP).

Conclusion: It is possible to synthesize TD and select the polymorph prepared by means of modulated solvent evaporation rate. The rank order of the intrinsic dissolution rate constants was TD-II > TD-I > $D A P$. The tosylate salt enhanced inhibitory effect on $M$. fortuitum, when compared to DAP.
\end{abstract}

Keywords: Dapsone tosylate, Polymorphism, Solid phase characteristics, Intrinsic dissolution, Antimycobacterium activity

This is an Open Access article that uses a funding model which does not charge readers or their institutions for access and distributed under the terms of the Creative Commons Attribution License (http://creativecommons.org/licenses/by/4.0) and the Budapest Open Access Initiative (http://www.budapestopenaccessinitiative.org/read), which permit unrestricted use, distribution, and reproduction in any medium, provided the original work is properly credited.

Tropical Journal of Pharmaceutical Research is indexed by Science Citation Index (SciSearch), Scopus, International Pharmaceutical Abstract, Chemical Abstracts, Embase, Index Copernicus, EBSCO, African Index Medicus, JournalSeek, Journal Citation Reports/Science Edition, Directory of Open Access Journals (DOAJ), African Journal Online, Bioline International, Open-J-Gate and Pharmacy Abstracts

\section{INTRODUCTION}

Dapsone (DAP, 4-((4-aminophenyl) sulfonyl) aniline, Figure 1) is an antimicrobial drug that is usually combined with rifampicin and clofazimine for the treatment Mycobacterium leprae [1]. It is also employed in clinical trials for the treatment 
of thrombocytopenia [2] and Henoch-Schönlein Purpura (childhood vasculitis) [3].<smiles>Nc1ccc(S(=O)(=O)c2ccc(N)cc2)cc1</smiles>

DAP<smiles>Cc1ccc([N+](=O)[O-])cc1</smiles>

TD

Figure 1: Chemical structure of dapsone (DAP) and dapsone tosylate (TD)

From the point of view of the solid drug, DAP has low aqueous solubility $\left(0.85 \mathrm{\mu g} \mathrm{ml}^{-1}\right.$, Tween 80$)$ [4], crystallizes in spatial group $\mathrm{P} 2{ }_{1} 2_{1} 2_{1}$ [5], and there are no reports of polymorphism at room temperature. However, it undergoes enantiotropic transformation ca $80{ }^{\circ} \mathrm{C}$ [6], and some solvates have been reported [7-9].

Several co-crystals, salts and synthetic derivatives of DAP with increased solubility, higher bioavailability and/or lower toxicity have been reported. Polymorphism has been reported in some cases. Four polymorphs of DAP-flavone co-crystals have been reported [10]. Acedapsone, a commercial derivative of DAP, has five polymorphs [11]. In both cases, the selection of the solvent for crystallization is crucial for achieving a single polymorph.

In spite of their reactivity and toxicity, sulfonate salts have become relevant in pharmaceutical sciences because of their polymorphic behavior, occurrence of solvates/hydrates, and increased solubility in aqueous media [12].

The preparation of DAP-tosylate (Figure 1) and its crystalline structure (CCDC code: PIXVEZ, TD-I) have been reported [13]. However, further studies related to solubility, thermal behavior and biopharmaceutical properties have not been carried out.

The present study was aimed at the preparation of a $5 \mathrm{~g}$-scale of TD, solid phase characterization of TD-I and TD-II (new TD polymorph), intrinsic dissolution rate of both TD polymorphs, and determination of preliminary antimicrobial activities.

\section{EXPERIMENTAL}

\section{Materials}

Dapsone (97 \%, CAS 88-08-0) and $p$ toluensulfonic acid ( $\geq 98.5 \%$ CAS 6192-52-5) were purchased from Sigma-Aldrich $\AA$, and were used without prior purification. Methanol $(\geq 99.9$ $\%$, CAS 67-56-1) and acetone (99.8\%, CAS $67-$ 64-1) were reagent grade, and were purchased from J.T. Baker. Müeller-Hinton broth was purchased from DIFCO®; solid TSA agar medium was obtained from BIOXON®; sterile $0.45 \mu \mathrm{m}$ membranes (titAn2) were product of Leacsa $\AA^{\circ}$, and WST-1 kit (cell culture colorimetric assay was purchased from Millipore $\AA$. Lamb blood was obtained from Microlab®. Mycobaterium fortuitum isolate was donated by Dr. Jorge Alberto Gonzalez y Merchand (Microbiology Department, ENCB-IPN, México).

\section{X-ray diffraction and spectroscopic studies}

Powder x-ray diffraction (PXRD) was performed on a Bruker D2-Phaser. The data were collected in the interval $5-50^{\circ}$ at $2 \theta$ angle, and at a progression of 0.02 . FT-IR spectra were recorded using Thermo Scientific Spectrophotometer Nicolet iS50 in the range of $4000-500 \mathrm{~cm}^{-1}$ with diamond ATR accessory. NMR- ${ }^{1} \mathrm{H}$ spectra were obtained on a Jeol ECA 500 spectrometer at room temperature, and DMSO- $d_{6}$ was used as solvent for all samples. DSC and TGA analyses were performed on TA instruments Q2000 and Q50, respectively. Each sample (ca $3 \mathrm{mg}$ ) was placed on sealed aluminum pans (DSC) or platinum baskets (TGA) and analyzed in the temperature range of 0 $400{ }^{\circ} \mathrm{C}$. A heating rate of $10^{\circ} \mathrm{C} \cdot \mathrm{min}^{-1}$ and a purge of nitrogen (flow rate, $100 \mathrm{ml} \cdot \mathrm{min}^{-1}$ ) were used for all samples.

\section{Studies on intrinsic dissolution rate}

The dissolution rate studies were carried out in a Wood apparatus (Varian $\AA$, VK7010) using a thermostated circulating water bath (Varian®), VK750D) at $100 \mathrm{rpm}$ and $37^{\circ} \mathrm{C}$. Aqueous $\mathrm{HCl}$ $(900 \mathrm{ml}, \mathrm{pH}$ 1.2) was used as dissolution medium at $100 \mathrm{rpm}$. A Zhermack hydraulic press (C305800 PO3) was employed for sample compression at $40 \mathrm{~kg} \cdot \mathrm{cm}^{-2}$ within $60 \mathrm{sec}$. The exposed surface had an area of $0.5 \mathrm{~cm}^{2}$. Samples of $3 \mathrm{ml}$ were taken at $5 \mathrm{~min}$ intervals from $t=5 \mathrm{~min}$ to $t=150 \mathrm{~min}$. The quantification of DAP and TD was performed by UV/vis spectroscopy. UV-vis spectra were collected using a Scinco® Spectrophotometer S-3100 and measured in the range of $200-800 \mathrm{~nm}$. 
Absorbance was measured at $290 \mathrm{~nm}$. All the procedures were carried out in triplicate.

\section{General procedure for preparation of DAP tosylate}

In a $100 \mathrm{ml}$ round-flask containing a magnetic stirrer, 1 eq. of DAP was dissolved in $\mathrm{V}_{1} \mathrm{ml}$ of an organic solvent. An aqueous solution of $p$ TSA was prepared using 1eq. of the acid and $\mathrm{V}_{2} \mathrm{ml}$ of deionized water. The pTSA solution was added drop by drop to the DAP solution. The final mixture was under one of the following conditions: (i) room temperature (RT) for $30 \mathrm{~min}$; (ii) $30{ }^{\circ} \mathrm{C}$ for $15 \mathrm{~min}$; (iii) refluxed for $15 \mathrm{~min}$. The reaction mixture was evaporated slowly (solvent evaporation at room temperature) or rapidly (rotary evaporator). The recovered solid was washed with acetone to remove DAP residues. The average yield was $90 \%$. The general procedure involved $1 \mathrm{mmol}, 3 \mathrm{mmol}$, and 10 mmol of DAP.

\section{Antimicrobial assay}

\section{Stock solutions}

Stock solutions of $1 \mathrm{mg} \cdot \mathrm{ml}^{-1}$ of DAP and TD were prepared by dissolving in $0.1 \% \mathrm{v} / \mathrm{v}$ DMSO and Müeller-Hinton broth. The solutions were further filtered through sterile $0.45 \mu \mathrm{m}$ membranes and kept at $-20^{\circ} \mathrm{C}$.

\section{Culture conditions for Mycobacterium fortuitum}

Cultures of Mycobacterium fortuitum were used on solid TSA agar medium supplemented with 10 $\%$ lamb blood and incubated at $37^{\circ} \mathrm{C}$ for $48 \mathrm{~h}$.

\section{Determination of anti-Mycobacterium activity}

Anti-Mycobacterium activity was carried out using 96-well plate microdilution method in accordance with CLSI guideline [14]. Inoculum of Mycobacterium fortuitum i.e. $1 \times 10^{8} \mathrm{UFC} / \mathrm{ml}(0.5$
MacFarland standard) was put in each well and challenged with varying concentrations $(0.125-$ $64 \mu \mathrm{g} / \mathrm{ml}$ ) of each compound at $37^{\circ} \mathrm{C}$ for $48 \mathrm{~h}$. For all assays, a control ( $M$. fortuitum without treatment), a column of blank wells (culture broth alone) and a column of reference wells (DAP) were included for comparative purposes. The anti-Mycobacterium activity was determined using WST-1 kit. Absorbance (A) was measured using a plate reader (Biorad®, Ultramark) at 490 $\mathrm{nm}$. Inhibition $(\mathrm{H})$ was computed from the absorbance of control group and the absorbance values of DAP and TD-treated groups using Eq 1.

$H(\%)=\{(A t-A b) /(A c-A b)\} 100$

where $A t, A b$ and $A c$ are the absorbance of treated, blank and control samples, respectively.

$\mathrm{MIC}, \mathrm{IC}_{90}$ and $\mathrm{IC}_{50}$ values were calculated using linear regression of inhibition versus concentration plots. The mean value and standard deviation (SD) were obtained from two independent assays performed in duplicate.

\section{RESULTS}

\section{Preparation of DAP tosylate}

To prepare TD in $5 \mathrm{~g}$-scale, it was necessary to study several conditions to establish how the organic solvent, solvent volume, reaction temperature, and evaporation rate affected the reaction product and its yield.

From Table 1, six lots of solids were obtained by varying solvent, temperature, reaction volume, and reaction temperature. The PXRD of every lot is shown in Figure 2. The PXRD pattern of Lot 1 did not fit with TD-I (calculated). Therefore, it was designated TD-II hereinafter. The reaction conditions for Lot 1(TD-II) and 6 (TD-I) were chosen to be scalable to $5 \mathrm{~g}$ of TD.

Table 1: Experimental conditions explored to prepare TD

\begin{tabular}{cccccccc}
\hline Lot & $\begin{array}{c}\text { DAP } \\
\text { (eq) }\end{array}$ & $\begin{array}{c}\text { pTSA } \\
\text { (eq) }\end{array}$ & $\begin{array}{c}\mathbf{V}_{\mathbf{1}} \\
\text { (solvent) }\end{array}$ & $\begin{array}{c}\mathbf{V}_{\mathbf{2}} \\
\text { (water) }\end{array}$ & $\begin{array}{c}\text { Temperature } \\
\text { Evaporation } \\
\text { rate }\end{array}$ & TD form \\
\hline 1 & 1 & 1 & Methanol $30 \mathrm{ml}$ & $5 \mathrm{ml}$ & Reflux & Fast & II \\
2 & 1 & 1 & Methanol $30 \mathrm{ml}$ & $5 \mathrm{ml}$ & Reflux & Slow & I \\
3 & 1 & 1 & Methanol $30 \mathrm{ml}$ & $5 \mathrm{ml}$ & RT & Slow & I \\
4 & 1 & 1 & Acetone $1 \mathrm{ml}$ & $1 \mathrm{ml}$ & RT & Slow & I \\
5 & 0.5 & 0.5 & Acetone $0.5 \mathrm{ml}$ & $0.5 \mathrm{ml}$ & $30^{\circ} \mathrm{C}$ & Slow & $\mathrm{I}$ \\
6 & 0.5 & 0.5 & Acetone $3 \mathrm{ml}$ & $1 \mathrm{ml}$ & $30^{\circ} \mathrm{C}$ & Slow & $\mathrm{I}$ \\
\hline
\end{tabular}


In particular, the conditions of Lot 6 were useful since a small amount of solvent permitted crystallization within a reasonable time lapse.

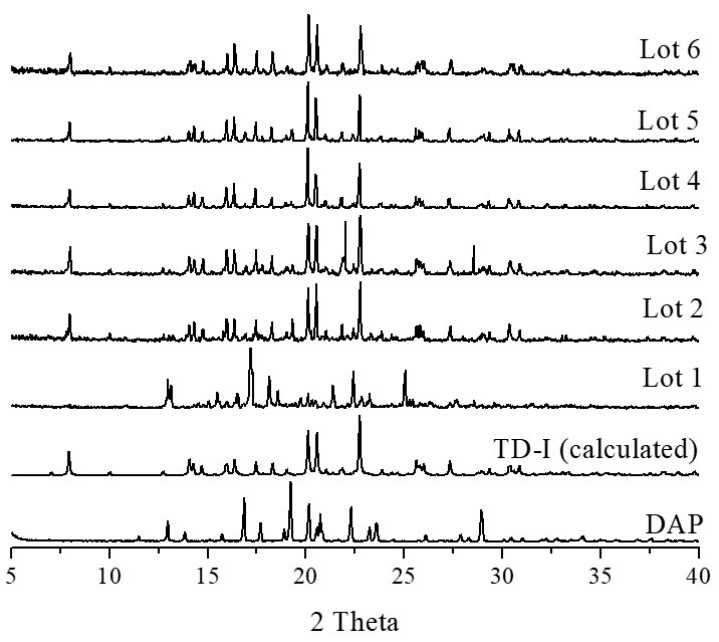

Figure 2: PXRD of lots prepared under conditions described in Table 1. TD-I (calculated) pattern was obtained from PIXVEZ [13] using the software, Mercury®

The ${ }^{1} \mathrm{H}$-NMR (DMSO- $d_{6}$ ) spectra of TD-I and TDII (Figure 3) showed the same signals except for the protons related to $\mathrm{N}-\mathrm{H}$ bonds that showed up at $6.90 \mathrm{ppm}$ (TD-II) and $7.50 \mathrm{ppm}$ (TD-I). These $\mathrm{N}-\mathrm{H}$ signals were overlapped with the aromatic signals and explain the discrepancy in integration values among both spectra. The signals in 6.65 ppm (TD-II, aromatic ring, 4H), 6.70 ppm (TD-I, aromatic ring, 4H), and $2.29 \mathrm{ppm}$ (TD-I, TD-II, $\mathrm{CH}_{3}, 3 \mathrm{H}$ ) indicate a $1: 1$ stoichiometry of DAP : pTSA in both samples. In the TD-I spectrum, a slight signal of acetone (2.08 ppm) was an artefact of the preparation process but it has no effect on the solid phase as shown in Figure 2.

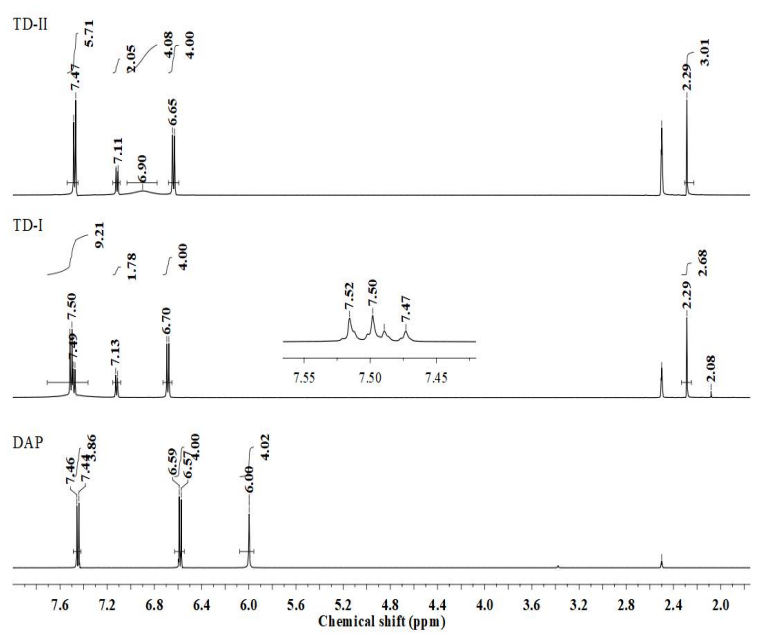

Figure 3: ${ }^{1} \mathrm{H}-\mathrm{NMR}(500 \mathrm{MHz})$ spectra of DAP, TD-I (Lot 6) and TD-II (Lot 1) in DMSO-d

\section{Thermal behavior}

Figure 4 shows the results of thermal analysis of DAP, TD-I and TD-II. The DSC curve of DAP shows its enantiotropic transformation at $82{ }^{\circ} \mathrm{C}$, melting point $\left(178{ }^{\circ} \mathrm{C}\right)$, and chemical decomposition above $350^{\circ} \mathrm{C}$.
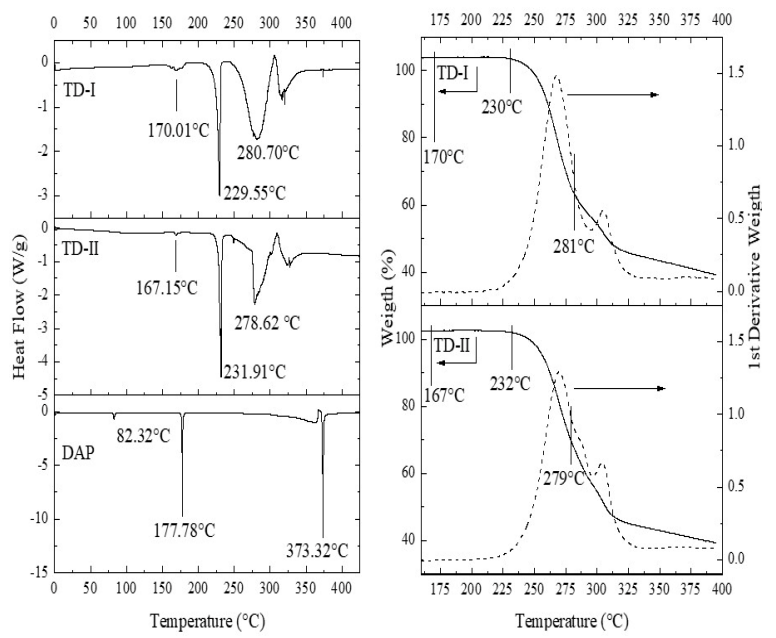

Figure 4: DSC (left) and TGA (right) analyses of DAP, TD-I and TD-II

Both TD polymorphs also presented three thermal events. Chemical decomposition occurred at $280{ }^{\circ} \mathrm{C}$ and was confirmed by TGA analysis (Figure 4, right) in which a loss of $60 \%$ of the starting sample was observed. The decomposition temperature was almost $90{ }^{\circ} \mathrm{C}$ lower than that of DAP. The melting points of TDI and TD-II occurred at 229 and $232{ }^{\circ} \mathrm{C}$, respectively. At $170{ }^{\circ} \mathrm{C}$, TD-I presented a polymorphic transformation to TD-II (no loss of matter was observed in TGA analysis at $170^{\circ} \mathrm{C}$ ). For TD-II sample, a small peak was observed at $167{ }^{\circ} \mathrm{C}$, as a possible consequence of a small remnant of TD-I formed during the synthesis.

\section{FT-IR spectra}

The spectra of TD-I and TD-II were closely related to those of DAP and pTSA (Figure 5). Bands associated with DAP moiety were observed in the region from 3460 to $3326 \mathrm{~cm}^{-1}$ $\left(\mathrm{v}_{\text {asym }}, \mathrm{v}_{\text {sym }}, \mathrm{N}-\mathrm{H},\right)$ and in the region of $730-710$ $\mathrm{cm}^{-1}$ ( $\left.\mathrm{T}, \mathrm{O}=\mathrm{S}-\mathrm{C}-\mathrm{C}\right)$ [15]. Bands of $p$ TSA moiety appeared from 2990 to $2560 \mathrm{~cm}^{-1}\left(v_{\text {asym }}, v_{\text {sym }}, C-\right.$ $\left.\mathrm{H}, \mathrm{CH}_{3}\right)$, at $1033 \mathrm{~cm}^{-1}(\mathrm{v}, \mathrm{C}-\mathrm{S})$, and in the region $864-845 \mathrm{~cm}^{-1}$ ( $\mathrm{Y}, \mathrm{C}-\mathrm{C}$, aromatic ring) [16].

Table 2 shows selected signals that belong to TD-I and TD-II. These signals (also indicated in Figure 5) were due to the anilinium moiety of the salt [17]. Signals 1 and 2 were due to saline bridge between the anilinium and sulfone 
moieties, while signal 3 was related to $\mathrm{NH}_{3}^{+}$ bending.

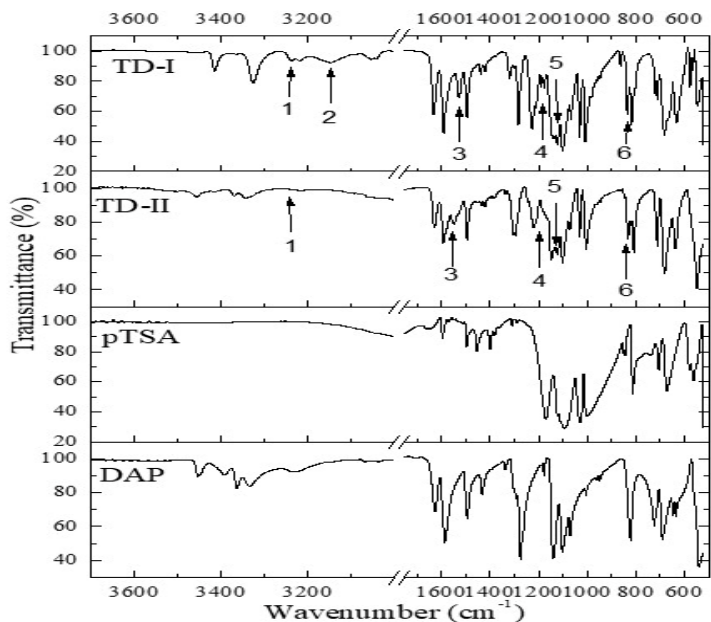

Figure 5: FT-IR spectra of DAP, pTSA, TD-I and TDII. The numbers are related to signals in Table 2 . For the sake of clarity, the region between 1700 and 3000 $\mathrm{cm}^{-1}$ has been omitted

Table 2: FT-IR bands associated with TD-I and TD-II

\begin{tabular}{|c|c|c|c|}
\hline No. & $\begin{array}{c}\text { TD-I } \\
\left(\mathrm{cm}^{-1}\right)\end{array}$ & $\begin{array}{l}\text { TD-II } \\
\left(\mathrm{cm}_{1}^{-}\right.\end{array}$ & Tentative assignation \\
\hline 1 & 3220 & 3216 & $\mathrm{v}\left(\mathrm{N}-\mathrm{H}^{+} \ldots \mathrm{O}-\mathrm{S}\right)$ \\
\hline 2 & 3147 & -- & $\mathrm{v}\left(\mathrm{N}-\mathrm{H}^{+} \ldots \mathrm{O}-\mathrm{S}\right)$ \\
\hline 3 & 1528 & 1548 & $\delta\left(\mathrm{NH}_{3}{ }^{+}\right)$ \\
\hline 4 & 1177 & 1166 & $\mathrm{v}\left(\mathrm{C}_{\text {arom}}-\mathrm{C}_{\mathrm{CH} 3},\right)+\delta\left(\mathrm{C}_{\text {arom }}-\mathrm{H}\right)$ \\
\hline 5 & 1124 & 1123 & $\mathrm{~V}_{\text {asym }}\left(\mathrm{SO}_{3}^{-}\right)+\delta\left(\mathrm{C}_{\text {arom }}-\mathrm{H}\right)$ \\
\hline 6 & 836 & 833 & $\mathrm{~V}\left(\mathrm{C}_{\text {arom }}-\mathrm{H}\right)+\mathrm{\gamma}(\mathrm{CCC})$ \\
\hline
\end{tabular}

Signals 4 and 6 were due to stretching and torsion vibrations of the tosylate aromatic fragment, while signal 5 was due to a stretching vibration of sulfonate anion as described by Ildiz and Akyuz [15].

\section{Intrinsic dissolution profiles}

The results from dissolution rate studies showed that TD-II released almost twice as much drug as TD-I and DAP at $150 \mathrm{~min}$ (Figure 6). Interestingly, only DAP had a linear profile, while TD-I and TD-II showed linear behavior below $t=$ $40 \mathrm{~min}$, but their slopes decreased thereafter.

The decreasing slope in both TD curves can be attributed to solid phase transformation. The PXRD of the solid remnant in the rotatory disk after dissolution experiment is shown in Figure 7. With TD-I as the starting solid phase, a clear transformation into TD-II occurred (Figure 7, left). On the other hand, TD-II was not efficiently transformed into TD-I during dissolution experiment (Figure 7, right).

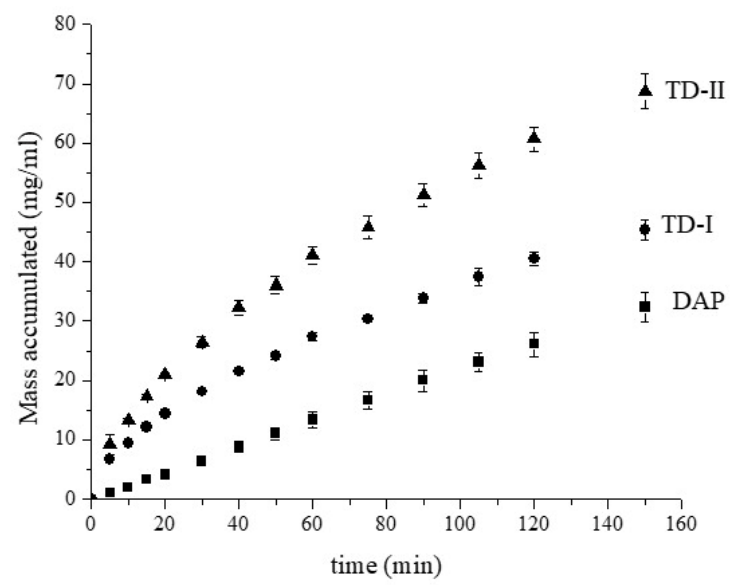

Figure 6: Intrinsic dissolution profiles of DAP, TD-I and TD-II. Experiments were carried out in $\mathrm{HCl}(\mathrm{pH}$ 1.2), $37^{\circ} \mathrm{C}$ and $100 \mathrm{rpm}$
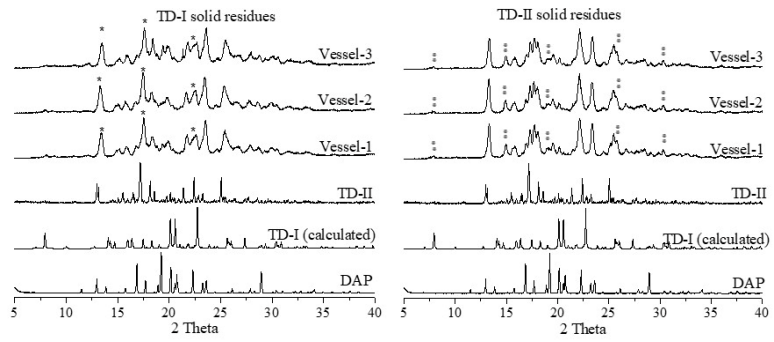

Figure 7: PXRD of solid residues recovered from dissolution rate studies. Signals associated with solidphase transformation are marked with * (TD-II) and ** (TD-I)

The dissolution rate constants (Table 3 ), calculated in the linear region (<40 min), showed that TD-II dissolved 3 and 1.5 times faster than DAP and TD-I, respectively.

Table 3: Intrinsic dissolution rate constants of synthesized compound and polymorphs

\begin{tabular}{ccc}
$\begin{array}{c}\text { Solid } \\
\text { phase }\end{array}$ & $\begin{array}{c}\boldsymbol{k}_{\text {int }} \mathbf{\pm} \text { SD } \\
\left(\mathbf{m g c m}^{-2} \mathbf{m i n}^{-1}\right)\end{array}$ & $\mathbf{r}$ \\
\hline DAP & $0.22 \pm 0.031$ & 0.997 \\
TD-I & $0.42 \pm 0.006$ & 0.990 \\
TD-II & $0.67 \pm 0.022$ & 0.991 \\
\hline
\end{tabular}

\section{Antimicrobial activity}

Mycobacterium fortuitum is classified as a rapid growing, non-tuberculous Mycobacterium (NTM) [18]. Mycobacterium fortuitum, like other NTM, is widely distributed around the world, and is responsible for lung infections and respiratory diseases [19]. 
Table 4: Mean values of MIC, $I_{90}$ and $I_{50}$ for DAP and TD

\begin{tabular}{|c|c|c|c|}
\hline $\begin{array}{l}\text { Com- } \\
\text { pound }\end{array}$ & $\begin{array}{c}\text { MIC } \pm \text { SD } \\
(\mu \mathrm{g} / \mathrm{ml})\end{array}$ & $\begin{array}{c}\mathrm{IC}_{90} \pm \mathrm{SD} \\
(\mu \mathrm{g} / \mathrm{ml})\end{array}$ & $\begin{array}{c}\mathrm{IC}_{50} \pm \mathrm{SD} \\
(\mu \mathrm{g} / \mathrm{ml})\end{array}$ \\
\hline DAP & $\begin{array}{c}32 \pm 0.007 \\
* 129 \mu \mathrm{M}\end{array}$ & $\begin{array}{c}29.78 \pm 6.56 \\
* 120 \mu \mathrm{M}\end{array}$ & $\begin{array}{c}5.71 \pm 0.183 \\
* 23 \mu \mathrm{M}\end{array}$ \\
\hline TD & $\begin{array}{c}32 \pm 0.002 \\
* 79.6 \mu \mathrm{M}\end{array}$ & $\begin{array}{c}16.82 \pm 2.6 \\
* 40.4 \mu \mathrm{M}\end{array}$ & $\begin{array}{c}1.39 \pm 0.16 \\
* 3.34 \mu \mathrm{M}\end{array}$ \\
\hline
\end{tabular}

In the present study, $M$. fortuitum was selected as microbiological model because of its rapid growth rate, and also because DAP has a poor, but measurable activity against it [20].

Table 4 shows that TD exerted improved antimycobacterium activity. The molar concentrations revealed that TD was more effective as an anti-mycobacterium agent than DAP because a lower molar mass of the drug was required to achieve the same inhibitory effect.

\section{DISCUSSION}

In this study, it is interesting that evaporation led to the formation of either TD-I or TD-II. On the other hand, heating had no effect on the resultant solid-phase. The formation of TD-I was independent of the solvent, but the formation of TD-II occurred only in methanol. FT-IR analysis showed differences in intensity between the TD polymorphs in the region of the saline bridge $\left(3150-3400 \mathrm{~cm}^{-1}\right)$. The low intensity signals for TD-II may be a consequence of low effective interaction among TD molecules in the solid. This may be responsible for the higher dissolution rate constant for TD-II. On the other hand, DSC analysis showed the transformation of TD-I to TD-II at $170{ }^{\circ} \mathrm{C}$. In addition, several attempts to obtain suitable TD-II crystals for single X-ray diffraction were not successful: only TD-I crystals were recovered.

These observations indicate that TD-I is a thermodynamic product. However, the energy barrier for polymorphic transformation was easily overcome when dissolution medium was in contact with any TD solid. In particular, the transformation TD-I $\rightarrow$ TD-II was preferred over the reverse process as suggested by PXRD results in which TD-I was transformed at the end of the dissolution experiment, but only a little amount of TD-I was observed when TD-II was the starting solid-phase.

$I_{50}$ data reveal that TD was more effective than DAP against $M$. fortuitum. This implies that permeation of TD was more efficient than that of DAP. There is no evidence-based explanation for this behavior.

\section{CONCLUSION}

A new polymorph of compound TD1 has been successfully prepared (TD-II). A method for the preparation of TD polymorphs on a $5 \mathrm{~g}$-scale has been developed. TD-I is transformed to TD-II at $170{ }^{\circ} \mathrm{C}$ or under liquid-assisted conditions. Although DAP is not employed for NTM, the tosylate salt displays improved drug activity against $M$. fortuitum.

\section{DECLARATIONS}

\section{Acknowledgement}

The authors acknowledge CONACyT and PRODEP for funding (nos. INF-2015-251898, INF-2013-204847, CB-2001-1(167351) and 103.5/14/10994. OTA and BEDM acknowledge $\mathrm{Dr}$ Jorge A Gonzalez y Merchand for donation of $M$. fortuitum isolate.

\section{Conflict of Interest}

No conflict of interest associated with this work.

\section{Contribution of Authors}

The authors declare that this work was done by the authors named in this article and all liabilities pertaining to claims relating to the content of this article will be borne by them.

\section{REFERENCES}

1. Cruz RCS, Bührer-Sékula S, Penna MLF PGO, Talhari S. Leprosy: current situation, clinical and laboratory aspects, treatment history and perspective of the uniform multidrug therapy for all patients. An Bras Dermatol 2017; 92(6): 761-773.

2. Esteve $C$, Samson M, Gulhem A, Nicolas B, LeguySeguin V, Berthier S, Bonnotte B, Audia S. Efficacy and safety of dapsone as second line therapy for adult immune thrombocytopenia: A retrospective study of 42 patients. PloS ONE 2017; 12(10): e0187296.

3. Hetland LE, Susrud KS, Lindahl KH, Bygum A. HenochSchönlein Purpura: A Literature Review. Acta Derm Venereol 2017; 97: 1160-1166.

4. Jiang L, Huang $Y$, Zhang $Q$, He $H, X u Y$, Mei $X$. Preparation and solid-state characterization of dapsone drug-drug co-crystals. Cryst Growth Des 2014; 14 (9): 4562-4573. 
5. Bertolasi V, Ferretti $V$, Gilli $P$, De Benedetti PG. Molecular structure and crystal packing of five 4aminophenul (4-substituted phenyl) sulfones. Correlations between structural distortions, spectroscopic parameters and electronics substituent effects. J Chem Soc Perkin Trans 1993; 213-219.

6. Yang TT, Swarbrick J. Sustained-release delivery system, I: Phase diagram studies of dapsone and selected derivatives. J Pharm Sci 1986; 75 (1): 53-56.

7. Lemmer $H$, Stieger $N$, Liebenberg $W$, Caira MR. Solvatomorphism of the antibacterial dapsone: $X$-ray structures and thermal desolvation kinetics. Cryst Growth Des 2012; 12 (3): 1683-1692.

8. Kuz'mina LG, Struchkov YT, Novozhilova NV, Tudorovskaya GL. Kristallografiya 1981; 26: 695.

9. Braun DE, Griesser UJ. Supramolecular organization of nonstoichiometric drug hydrates: Dapsone. Frontiers in Chemistry 2018; (6): A31.

10. He $H$, Jiang L, Zhang $Q$, Huang $Y$, Wang JR, Mei $X$. Polymorphism observed in dapsone-flavone cocrystals that present pronounced differences in solubility and stability. CrystEngComm 2015; 17: 6566-6574.

11. Bolla G, Mittapalli S, Nangia A. Pentamorphs of Acedapsone. Cryst Growth Des 2014; 14 (10): 5260 5274.

12. Elder DP, Delaney E, Teasdale A, Eyley S, Reif VD, Jacq K, Facchine KL, Oestrich RS, Sandra P, David F. J Pharm Sci 2010; 99(7): 2948-2961.

13. Smith G, Wermuth UD. 4-(4Aminophenylsulfonyl)aniliniumtoluene-4-sulfonate. Acta Cryst 2014; E70: 037.

14. Woods GL, Pfyffer GE, Brown-Elliott BA, Ridderhof JC, Conville PS, Siddiqi SH, Desmond EP, Wallace RJ, Hall
GS, Warren NG, et al, editors. Susceptibility testing of Mycobacteria, Nocardiae, and other Actinomycetes; Approved standard - Second Edition. Pennsylvanya: CLSI document M24-A2 (ISBN: 1-56238-746-4); 2011.

15. Ildiz GO, Akyuz S. Conformational analysis and vibrational spectroscopic studies on dapsone. Opt Spectrosc 2012; 113 (5): 495-504.

16. Pejov L, Ristova M, Soptrajanov B. Quantum chemical study of p-toluenesulfonic acid, p-toluenesulfonate anion and the water-p-toluenesulfonic acid complex. Comparison with experimental spectroscopic data. Spectrochimic Acta A 2011; 79 (1): 27-34.

17. Matulková I, Cihelka J, Fejfarová K, Dusek M, Pajarová $M$, Vanek P, Kroupa J, Sala M, Krupková R, Nemec I. Semi-organic salts of aniline with inorganic acids: prospective materials for the second harmonic generation. CrystEngComm 2011; 13(12): 4131-4138.

18. Griffith DE, Aksamit T, Bown-Elliott BA, Catanzaro A, Daley C. An official ATS/IDSA statement: diagnosis, treatment, and prevention of nontuberculous mycobacterial diseases. Am J Respir Crit Care Med 2007; 175: 367-416.

19. Papadopoulou MV, Bloomer HS, Arena A, Arrieta F, Rebolledo JCJ, Smith DK. Nitrotriazole- and imidazolebased amides and sulfonamides as antitubercular agents. Antimicrob Agents Chemother 2014; 58(11): 6828-6836.

20. Pang H, Li G, Zhao X, Liu H, Wan K, Yu P. Drug susceptibility testing of 31 antimicrobial agents on rapidly growing mycobacteria isolates from china. Biomed Res Int 2015; 2015: ID 419392. 